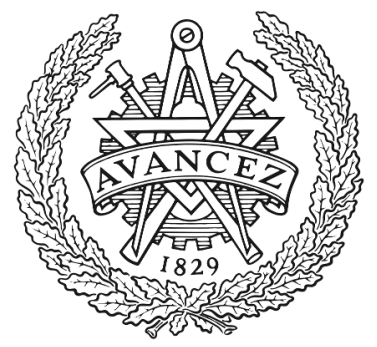

CHALMERS

UNIVERSITY OF TECHNOLOGY

\title{
Global Kinetic Model of a Three-Way-Catalyst-Coated Gasoline Particulate Filter: Catalytic Effects of Soot Accumulation
}

Downloaded from: https://research.chalmers.se, 2023-04-26 14:28 UTC

Citation for the original published paper (version of record):

De Abreu Goes, J., Olsson, L., Watling, T. (2021). Global Kinetic Model of a

Three-Way-Catalyst-Coated Gasoline Particulate Filter: Catalytic

Effects of Soot Accumulation. Industrial \& Engineering Chemistry Research, 60(47): 16899-16910.

http://dx.doi.org/10.1021/acs.iecr.1c02742

N.B. When citing this work, cite the original published paper. 


\title{
Global Kinetic Model of a Three-Way-Catalyst-Coated Gasoline Particulate Filter: Catalytic Effects of Soot Accumulation
}

\author{
Jesus De Abreu Goes, Louise Olsson,* and Timothy C. Watling
}

Cite This: Ind. Eng. Chem. Res. 2021, 60, 16899-16910

Read Online

ACCESS

Llll Metrics \& More

Article Recommendations

Supporting Information

\section{Global Kinetic Model of a TWC-Coated GPF}
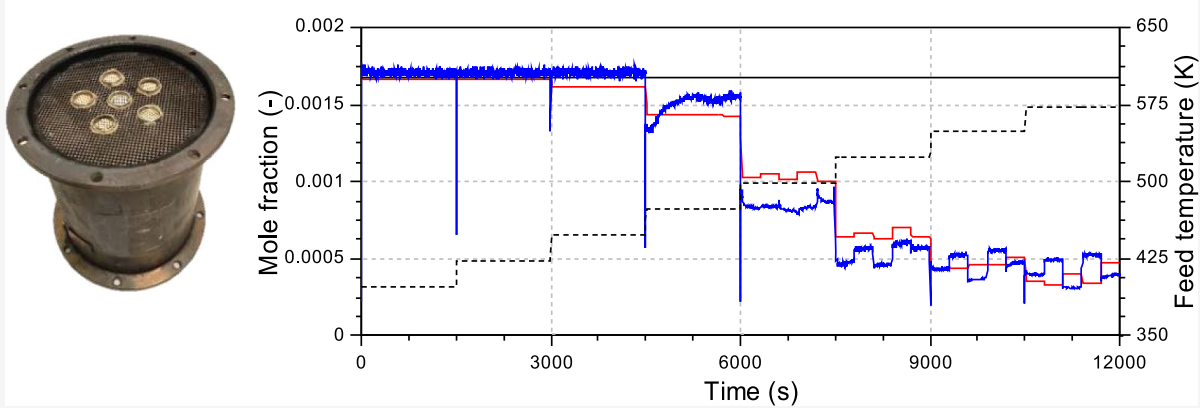

ABSTRACT: In the present study, a global kinetic model of three-way-catalyst-coated gasoline particulate filters was developed to understand the relevant kinetic mechanisms taking place both in clean and real soot-loaded filters. The model involves reaction rate expressions for $\mathrm{CO}, \mathrm{C}_{2} \mathrm{H}_{4}$, and $\mathrm{C}_{7} \mathrm{H}_{8}$ conversion over a model $\mathrm{Pd} / \mathrm{CeZr} / \mathrm{Al}_{2} \mathrm{O}_{3}$ catalyst, hydrothermally treated at $650{ }^{\circ} \mathrm{C}$. Particularly, a new rate expression was proposed for ethylene based on the distinctive experimental trends observed for this hydrocarbon. The model predicted satisfactorily the conversion of all three reductants under different experimental conditions. The soot inhibition effect was also modeled by the reduction of the number of active sites. Interestingly, ethylene was less affected compared to other reductants by the presence of soot due to the formation of less stable and more reactive species on the catalyst surface.

\section{INTRODUCTION}

The three-way catalyst (TWC) converter is a widely and successfully utilized component for the removal of carbon monoxide ( $\mathrm{CO}$ ), unburned hydrocarbon ( $\mathrm{HC})$, and nitrogen oxide $\left(\mathrm{NO}_{x}\right)$ pollutants of stoichiometric engines. As the emission limits are becoming more rigorous, the design and optimization of TWCs are being increasingly supported by mathematical modeling, reducing the amount of experimentation required. This approach particularly needs a detailed understanding of the relevant reaction mechanisms and kinetic processes taking place simultaneously and interactively over the whole range of operating conditions. Multiple models have appeared in the literature describing these mechanisms over TWC converters with varying degrees of complexity. For instance, Dubien et al. ${ }^{1}$ developed kinetic expressions for fastand slow-oxidizing hydrocarbons, inhibiting species and steam reforming reactions over TWC based on the widely used rate expressions proposed by Voltz et al. ${ }^{2}$ and Subramanian and Varma. $^{3}$ Nibbelke et al. ${ }^{4,5}$ developed a steady-state and transient microkinetic model for the $\mathrm{CO}$ oxidation over a $\mathrm{Pt} / \mathrm{Rh} / \mathrm{CeO}_{2} / \mathrm{Al}_{2} \mathrm{O}_{3}$ catalyst formulation. More recently, Hauck et al. ${ }^{6}$ simulated the $\mathrm{CO}$ oxidation over pretreated and aged $\mathrm{Pd} / \mathrm{Rh}$-based commercial TWC converters using a microkinetic reaction model. Kang et al. ${ }^{7}$ developed reaction kinetics for a $\mathrm{Pd} / \mathrm{Rh}$ double-layered TWC by combining the activity function derived for the Pd-based and Rh-based catalysts. Kang et al. $^{8}$ also developed a model capable of predicting the change of the catalytic performance by catalyst mileage. Additionally, Ramanathan et al. ${ }^{9}$ employed different vehicle data sets to estimate the kinetic parameters of a TWC global kinetic model. The model was able to predict the lightoff temperature of new data sets reasonably well.

New emission regulations have not only introduced more rigorous limits for gaseous pollutants but also for particle emissions. The latest European emission regulations are set on the basis of both mass and number counts to guarantee the reduction of the ultrafine particles. ${ }^{10}$ The PM and PN European regulation (Euro $6 \mathrm{c}$ ) are set at $4.5 \mathrm{mg} / \mathrm{km}$ and 6

Received: July 11, 2021

Revised: October 21, 2021

Accepted: October 22, 2021

Published: November 10, 2021

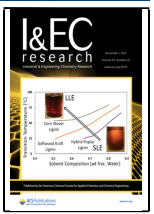




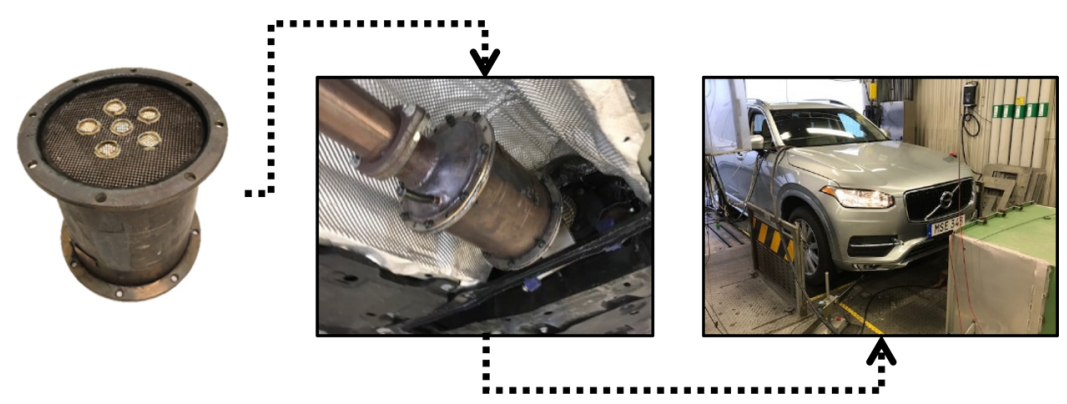

Figure 1. Real soot collection procedure based on $10 \mathrm{~h}$ running aggressive RDE cycles in the vehicle chassis dynamometer. The injection timing and lambda set-point were modified to accelerate the soot collection.

$\times 10^{11} \# / \mathrm{km}$, on the World-Harmonized Light-duty Test Cycle, WLTC. ${ }^{11-13}$ In addition, particle number regulations of $9 \times 10^{11} \# / \mathrm{km}$ should also be followed under real driving conditions (Euro 6d-TEMP). ${ }^{11}$ PM regulations in US (California LEVIII and US Tier 3) require vehicles to emit less than $3 \mathrm{mg} / \mathrm{mi}$ by 2021 and further down to $1 \mathrm{mg} / \mathrm{mi}$ in California from 2025. ${ }^{14,15}$ Meanwhile, China is following the European framework with some variations. ${ }^{11}$

Therefore, in order to comply with current and future PM/ PN limits, it is very likely that car manufacturers will equip gasoline-powered vehicles with gasoline particulate filters (GPFs). It is likely that the most economical way to use this technology in a gasoline exhaust system is by combining TWC + GPF in one single device (referred to as a catalyzed gasoline particulate filter (cGPF), or four-way catalyst). ${ }^{16,17}$ This technology consists of a TWC catalytic material impregnated on the porous walls of the particle filter. This system configuration may bring potential benefits in terms of vehicle system configuration and overall cost. ${ }^{13}$ For vehicles with very little ground clearance, the filter must be mounted in a location close to the engine. ${ }^{14}$ This technology can be also mounted in the underbody position, downstream of the TWC(s). In this case, the system will be colder and will tend to trap more soot. ${ }^{14}$ Some research work has already been done for cGPF technology, and it is expected to be adopted extensively in the future. $^{12,13,16-20}$ However, cGPFs need to take into account both the effect of soot and ash loading. It is well documented that the TWC functionality of cGPFs is affected in the presence of ash. ${ }^{13,17,20}$ In an earlier publication, ${ }^{21}$ the catalytic performance of soot-free and soot-loaded samples was compared under different feed temperatures and feed gas mixtures. It was demonstrated that the soot accumulation on cGPFs has a large effect on the gaseous pollutant conversion due to the deposition of soot onto their active sites. This soot inhibition effect, which is negligible in TWC converters because of their inherent low filtering efficiency, is simulated in the present study with a global kinetic model.

The objective of this article is to understand the relevant TWC reaction mechanisms and kinetic processes taking place both in clean and soot-loaded filters. The model captures most of the experimental trends reported in the previous publication, particularly when using a $\mathrm{Pd} / \mathrm{CeZr} / \mathrm{Al}_{2} \mathrm{O}_{3}$-coated GPF converter.

\section{EXPERIMENTAL PROCEDURE}

2.1. Catalyst Preparation. The preparation of the $\mathrm{CeZrO}_{2} / \gamma-\mathrm{Al}_{2} \mathrm{O}_{3}$ catalyst support was done by a citrate complexation incipient wetness impregnation method, ${ }^{22-24}$ details of which can be found in our earlier publication. ${ }^{21}$
Thereafter, 0.92 wt $\%$ palladium was then added to the support $\mathrm{CeZrO}_{2} / \gamma-\mathrm{Al}_{2} \mathrm{O}_{3}$ using the incipient wetness impregnation method. The $\mathrm{Pd}\left(\mathrm{NO}_{3}\right)_{2}$ (Heraeus $\mathrm{GmbH}, 16.37$ wt \% Pd, Hanau, Germany) precursor was first dissolved in deionized water and impregnated on to the support. The material was dried at $110{ }^{\circ} \mathrm{C}$ and calcined at $550{ }^{\circ} \mathrm{C}$ for $2 \mathrm{~h} . \mathrm{Pd} / \mathrm{CeZr} /$ $\mathrm{Al}_{2} \mathrm{O}_{3}$ was washcoated onto a commercial GPF substrate intended for coating. The substrate was $300 \mathrm{cpsi}$, with a wall thickness of $8 \mathrm{mil}$. The dimension was $13 \mathrm{~mm}$ in diameter and $20 \mathrm{~mm}$ in length, with a washcoat loading of $270 \mathrm{mg}$.

2.2. Soot Collection. Before collecting the soot, the monolith was treated for $20 \mathrm{~h}$ at $650{ }^{\circ} \mathrm{C}$ in $5 \% \mathrm{H}_{2} \mathrm{O}$ and $10 \%$ $\mathrm{O}_{2}$, using a total flow of $3 \mathrm{~L} / \mathrm{min}$ with Ar balance at atmospheric pressure. After this, every second channel of the monolith was plugged at each end using a slurry (95 wt \% $\theta$ $\mathrm{Al}_{2} \mathrm{O}_{3}$ and 5 wt \% binder (boehmite Disperal P2, Sasol, Brunsbüttel, Germany)). The monoliths were thereafter dried and calcined at $550{ }^{\circ} \mathrm{C}$ for $2 \mathrm{~h}$. The monolith was then fitted into a modified commercial GPF converter, as shown in Figure 1 , and installed in the underbody of a gasoline Volvo Cars vehicle. Aggressive RDE cycles were run on the vehicle chassis dynamometer for $10 \mathrm{~h}$ to collect real soot. The aggressive RDE cycle is often denoted as the RTS95 cycle, which was developed based on the WLTP database with high representation of high load and high speed engine operating points. Note that the lambda set-point and injection timing were changed to increase the soot amount, to facilitate the collection of soot. The amount of soot loaded can be estimated based on $\mathrm{CO}_{2}$ production when oxidizing the soot, which can be found in our previous publication. ${ }^{21}$

2.3. Catalyst Characterization. Transmission electron microscopy (TEM) analysis was conducted to determine the average Pd particle size. After the flow-reactor tests, part of the catalyst powder was scraped off from the monolith for TEM analysis. The catalyst powder was ground in an agate mortar and then placed on a carbon film employing TEM $\mathrm{Cu}$ grids. Samples were imaged using an FEI Titan 80-300 TEM. The images were collected using a high-angle annular dark field detector in the scanning TEM (STEM) imaging mode. Energy-dispersive spectroscopy was also employed to determine the presence of precious metals. Particle size analysis was performed with ImageJ.

The measurement of the specific surface area was also performed by using the nitrogen physisorption method at $-196{ }^{\circ} \mathrm{C}$ on a Micromeritics TriStar 3000 instrument. Half of the sample monolith was crushed and pretreated in a vacuum at $225^{\circ} \mathrm{C}$ for $2 \mathrm{~h}$. The specific surface area was obtained from the linear part of the Brunauer-Emmett-Teller (BET) curve. Moreover, the specific surface area of the substrate was 
measured and subtracted from the measured BET curve of the real samples.

Additionally, the coated GPF sample was studied in sections using elemental mappings by scanning electron microscopy and energy-dispersive X-ray (SEM-EDX). The experiment was performed in low-vacuum mode using an FEI Quanta 200 ESEM equipped with an Oxford Inca EDX.

2.4. Flow-Reactor Experiments. The catalytic activity of the sample was tested in a continuous gas flow reactor, which consisted of a horizontal quartz tube with heating and insulation. The monolith was wrapped in an inert expandable mat to hinder bypass of the gas flow. The temperature was measured using two K-type thermocouples. One thermocouple was placed $10 \mathrm{~mm}$ upstream the monolith to measure the temperature of the gas phase, while the second was located in the rear part of the monolith to monitor the reaction temperature. The total flow rate was kept constant at 4000 $\mathrm{mL} / \mathrm{min}$ throughout the course of each experiment by use of Ar balance. The inlet gas composition was controlled by separate mass flow controllers (Bronkhorst), while the reactor outlet composition was measured with a calibrated FTIR spectrometer (MKS $2030 \mathrm{HS}$ ).

Prior to testing, a pretreatment procedure was carried out at $550{ }^{\circ} \mathrm{C}$ for $1 \mathrm{~h}$ in the presence of Ar. Then, the catalytic activity of the soot-free sample was tested under steady-state conditions from 200 to $500{ }^{\circ} \mathrm{C}$ in the presence of different reductants: carbon monoxide $(1 \% \mathrm{CO})$, ethene $\left(0.17 \% \mathrm{C}_{2} \mathrm{H}_{4}\right)$, and toluene $\left(560 \mathrm{ppm} \mathrm{C}_{7} \mathrm{H}_{8}\right)$. The feed gas mixture was composed of $\mathrm{CO} /$ hydrocarbon, $\mathrm{O}_{2}$ (adjustable), $\mathrm{CO}_{2}$ (12\%), and $\mathrm{H}_{2} \mathrm{O}(5 \%)$. The $\mathrm{O}_{2}$ concentration was adjusted during the experiment to achieve different $\lambda$-values, ranging from 0.85 to 1.15 , as presented in Figure 2. Note that lambda $(\lambda)$

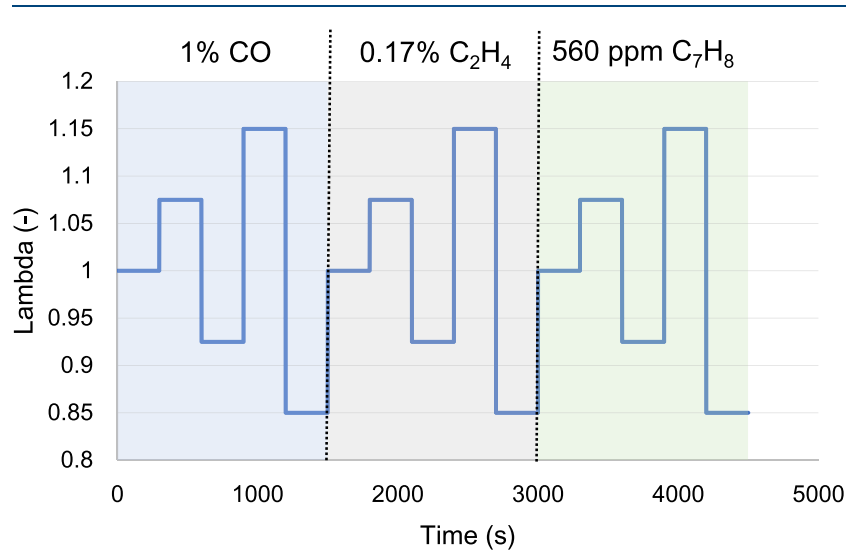

Figure 2. Inlet gas composition at constant temperature using carbon monoxide $(1 \% \mathrm{CO})$, ethene $\left(0.17 \% \mathrm{C}_{2} \mathrm{H}_{4}\right)$, or toluene $(560 \mathrm{ppm}$ $\mathrm{C}_{7} \mathrm{H}_{8}$ ) in the presence of $\mathrm{O}_{2}$ (adjustable), $\mathrm{CO}_{2}(12 \%)$, and $\mathrm{H}_{2} \mathrm{O}$ $(5 \%)$.

corresponds to the ratio between the existing oxygen and the oxygen that is required to reach full conversion. Thereafter, the soot-loaded sample was tested following the same procedure described above, except that in this case, the reactor temperature was limited between 125 and $300{ }^{\circ} \mathrm{C}$ to prevent soot being burned off. Further information regarding the soot oxidation profile is shown in our earlier publication. ${ }^{21}$

\section{MODEL DEVELOPMENT}

3.1. Reactor Model. The kinetic model of a TWC-coated GPF was developed in the simulation framework of AVL BOOST aftertreatment. The filter geometry is reduced to one single 1D pair of inlet and outlet channels that are connected by a porous wall. For simplicity, the soot accumulated on the filter is assumed to be located on the filter wall with no soot penetration into the wall. Radial mass transfer from the inlet channel through the wall into the outlet channel is considered in the filter model. The species mass balance equations in the inlet (1) and outlet (2) channels are given by ${ }^{25}$

$$
\begin{aligned}
\frac{\partial\left(m_{\mathrm{gi}} w_{\mathrm{gi}, \mathrm{j}}\right)}{\partial t}= & -\frac{\partial\left(\dot{m}_{\mathrm{gi}} w_{\mathrm{gi}, \mathrm{j}}\right)}{\partial z} d z-\dot{m}_{\mathrm{gis}} w_{\mathrm{gis}, \mathrm{j}} \\
& -\rho_{\mathrm{gis}} A_{\mathrm{gis}} \beta_{\mathrm{gis}}\left(w_{\mathrm{gi}, \mathrm{j}}-w_{\mathrm{gis}, \mathrm{j}}\right) \\
\frac{\partial\left(m_{\mathrm{go}} w_{\mathrm{go}, \mathrm{j}}\right)}{\partial t}= & -\frac{\partial\left(\dot{m}_{\mathrm{go}} w_{\mathrm{go}, \mathrm{j}}\right)}{\partial z} d z+\dot{m}_{\mathrm{gon}} w_{\mathrm{gon}, \mathrm{j}} \\
& -\rho_{\mathrm{gon}} A_{\mathrm{gon}} \beta_{\mathrm{gon}}\left(w_{\mathrm{go}, \mathrm{j}}-w_{\mathrm{gon}, \mathrm{j}}\right)
\end{aligned}
$$

where the time derivative of the inlet and outlet channel masses $\left(m_{\mathrm{gi}}\right.$ and $\left.m_{\mathrm{go}}\right)$ balances the spatial $z$ (axial direction along the channels) derivative of the mass fluxes $\left(\dot{m}_{\mathrm{gi}}\right.$ and $\left.\dot{m}_{\mathrm{go}}\right)$, reduced or augmented by two additional wall flow source terms. The first term (second on the right side) is associated with the advective species transfer between channels and walls, whereas the third term on the right side is attributed to the species transfer following the film model. The variables $w_{\mathrm{gi}, \mathrm{j}}$ and $w_{\mathrm{go}, \mathrm{j}}$ represent the mass fraction of species $j$ in the inlet and outlet channels, whereas $w_{g i s, j}$ and $w_{g o n, j}$ are the mass fraction of species $j$ from the inlet channel into the wall and from the wall into the outlet channel, respectively. The gas density is denoted by $\rho_{\text {gis }}$ at the inlet channel-substrate interface and $\rho_{\text {gon }}$ at the outlet channel-substrate interface. $A_{\text {gis }}$ and $A_{\text {gon }}$ represent the wall surface area in the inlet and outlet channels. Also, $\beta$ is the mass transfer coefficient of the individual species calculated according to

$$
\beta_{j}=\frac{S h \times D_{j}}{d_{\text {hyd }}}
$$

where $S h$ is the Sherwood number for fully developed laminar flows in a circular channel $(S h=3.657),{ }^{26} D_{j}$ is the diffusion coefficient, and $d_{\text {hyd }}$ represents the hydraulic diameter of the channel.

Moreover, the gas species balance in the porous wall is given by $^{25}$

$$
\begin{aligned}
\frac{\partial\left(m_{\mathrm{gw}} w_{\mathrm{gw}, \mathrm{j}}\right)}{\partial t}= & -\frac{\partial\left(\dot{m}_{\mathrm{gw}} w_{\mathrm{gw}, \mathrm{j}}\right)}{\partial x} d x+D_{w} \frac{\partial}{\partial x}\left(A_{\mathrm{w}} \rho_{\mathrm{w}} \frac{d w_{\mathrm{gw}, \mathrm{j}}}{d x}\right) d x \\
& +A_{\mathrm{w}} d x M G_{\mathrm{j}} \sum v_{\mathrm{w}, \mathrm{i}, \mathrm{j}} \dot{r}_{\mathrm{w}, \mathrm{i}}\left(y_{\mathrm{j}}, T_{\mathrm{s}}, \theta_{\mathrm{j}}\right)
\end{aligned}
$$

where the time derivative of the wall mass $\left(m_{\mathrm{gw}}\right)$ balances the spatial $x$ derivative (along the porous filter wall structure) of the mass fluxes $\left(\dot{m}_{\mathrm{gw}}\right)$, changed by additional diffusive (according to Fick's law) and surface storage and reaction terms. $M G_{j}$ corresponds to the molar mass of species $j$, and $\dot{r}_{\mathrm{w}, \mathrm{i}}$ is the specific molar reaction rate at the wall multiplied by the stoichiometric coefficient $v_{\mathrm{w}, \mathrm{i}, \mathrm{j}}$. 
The reaction heat was simulated using heat balances built into AVL BOOST software. The energy balance in the gas phase is

$$
\begin{aligned}
\varepsilon_{\mathrm{g}} & \frac{\partial}{\partial t}\left(\rho_{\mathrm{g}} \sum_{k}^{K} \omega_{\mathrm{k}, \mathrm{g}} h_{\mathrm{k}}\right) \\
= & -\varepsilon_{\mathrm{g}} \frac{\partial}{\partial z}\left(\rho_{\mathrm{g}} \sum_{k}^{K} \omega_{\mathrm{k}, \mathrm{g}} h_{\mathrm{k}} v_{\mathrm{g}}\right)+\varepsilon_{\mathrm{g}} \frac{\partial}{\partial z}\left(\lambda_{\mathrm{g}} \frac{\partial T_{\mathrm{g}}}{\partial z}\right) \\
& +\sum_{k}^{K} \varepsilon_{\mathrm{g}} \frac{\partial}{\partial z}\left(\rho_{\mathrm{g}} D_{\mathrm{eff}} \frac{\partial \omega_{\mathrm{k}, \mathrm{g}}}{\partial z} h_{\mathrm{k}}\right)+\operatorname{GSA} k_{\mathrm{h}}\left(T_{\mathrm{s}}-T_{\mathrm{g}}\right)
\end{aligned}
$$

where $\varepsilon_{\mathrm{g}}$ is the volume fraction of the gas phase, $T_{\mathrm{g}}$ is the gasphase temperature, $h_{\mathrm{k}}$ is the total enthalpy of component $\mathrm{k}, \lambda_{\mathrm{g}}$ is the thermal conductivity of the gas phase, $k_{\mathrm{h}}$ is the heat transfer coefficient, and GSA is the total channel surface area per unit of substrate volume.

The solid-phase energy balance equation is shown in eq 6

$$
\begin{aligned}
(1 & \left.-\varepsilon_{\mathrm{g}}\right) \rho_{\mathrm{s}} \frac{\partial\left(c_{\mathrm{p}, \mathrm{s}} T_{\mathrm{s}}\right)}{\partial t} \\
= & \left(1-\varepsilon_{\mathrm{g}}\right) \frac{\partial}{\partial z}\left(\lambda_{\mathrm{s}} \frac{\partial T_{s}}{\partial z}\right)-\text { GSA } k_{\mathrm{h}}\left(T_{\mathrm{s}}-T_{\mathrm{g}}\right) \\
& +\sum_{i}^{I} \Delta h_{\mathrm{i}} r_{\mathrm{i}}\left(c_{\mathrm{k}}^{\mathrm{L}}, T_{\mathrm{s}}\right)
\end{aligned}
$$

where $\rho_{s}$ is the density of the solid phase, $\lambda_{s}$ is the thermal conductivity of the solid phase, and $\Delta h_{\mathrm{i}}$ is the heat of reaction.

3.2. Kinetic Model. This work is a continuation of an earlier publication, where the conversion and durability of model cGPF catalysts were examined experimentally for different temperatures and gas compositions. ${ }^{21}$ Based on these experimental results, a global kinetic model was then developed in the current work to capture the $\mathrm{CO}, \mathrm{C}_{2} \mathrm{H}_{4}$, and $\mathrm{C}_{7} \mathrm{H}_{8}$ conversion behavior both in soot-free and soot-loaded cGPFs. All reaction mechanisms of this kinetic model are described below and summarized in Tables $1-5$. Note that the

Table 1. Reactions and Rate Expressions for CO Oxidation and Water-Gas Shift Reactions

$$
\text { reaction }
$$
kinetic rate expression

$$
\begin{array}{ll}
\mathrm{CO}+\mathrm{O}_{2} \rightarrow \mathrm{CO}_{2} & r_{1}=\frac{\mathrm{Pd}_{\text {site }} k_{1} y_{\mathrm{CO}} y_{\mathrm{O}_{2}}}{\left(1+K_{1}^{\text {inh }} y_{\mathrm{CO}}\right)^{2}} \\
\mathrm{CO}+\mathrm{H}_{2} \mathrm{O} \leftrightharpoons \mathrm{CO}_{2}+\mathrm{H}_{2} & r_{2}=\mathrm{Pd}_{\text {site }} k_{2 \mathrm{f}}\left(y_{\mathrm{CO}} y_{\mathrm{H}_{2} \mathrm{O}}-\frac{y_{\mathrm{H}_{2}} y_{\mathrm{CO}}}{K_{\mathrm{eq}_{2}}}\right)
\end{array}
$$

total reaction rates are expressed in $\mathrm{kmol} / \mathrm{s} / \mathrm{m}^{3}$ (filter volume). These expressions consider the number of active sites taking place in the reaction, which depends on the active metal loading level and dispersion. Likewise, the Arrhenius equation was used in this study to calculate the rate constants $(k)$ according to

$$
k_{\mathrm{i}}=A_{\mathrm{i}} e^{-E_{A_{\mathrm{i}}} / R T_{\mathrm{s}}}
$$

where $A_{\mathrm{i}}$ is the pre-exponential factor, $E_{\mathrm{Ai}}$ the activation energy $\left(\mathrm{J} \mathrm{mol}^{-1}\right), R$ the gas constant $\left(8.314 \mathrm{~J} \mathrm{~mol}^{-1} \mathrm{~K}^{-1}\right)$, and $T_{\mathrm{s}}$ the substrate temperature $(\mathrm{K})$.
3.2.1. CO Abatement Reactions. CO abatement processes, such as $\mathrm{CO}$ oxidation (preferential reaction) and water-gas shift (WGS) reaction, are simulated in this work. First, the rate of CO oxidation was modeled using a Langmuir-Hinshelwood rate expression previously presented by Etheridge and Watling $^{27}$ (see Table $1 \mathrm{R} 1$ ). In this expression, $P d_{\text {site }}$ is the site density, $k_{1}$ is the rate constant, $y_{\mathrm{CO}}$ and $y_{\mathrm{O} 2}$ are the mole fractions of $\mathrm{CO}$ and $\mathrm{O}_{2}$, respectively, and $K_{1}^{\mathrm{inh}}$ is the inhibition term, which takes into account the inhibition effect of $\mathrm{CO}$ adsorption on the overall reaction rate. $K_{1}^{\text {inh }}$ has no influence on the reaction rate at low concentrations of $\mathrm{CO}\left(K_{1}^{\mathrm{inh}} y_{\mathrm{CO}} \ll\right.$ 1 ), and thus, under such conditions, the $\mathrm{CO}$ oxidation rate is first order with respect to both $\mathrm{O}_{2}$ and $\mathrm{CO}$ concentrations. As the $\mathrm{CO}$ concentration increases, the $K_{1}^{\text {inh }}$ term becomes important $\left(K_{1}^{\mathrm{inh}} y_{\mathrm{CO}} \gg 1\right)$, resulting in shifting the kinetic order of $\mathrm{CO}$ oxidation from positive to negative first order with respect to the $\mathrm{CO}$ concentration. It is important to mention that the $\mathrm{CO}$ oxidation rate expression used in this work is similar to the classical kinetic equation presented by Voltz et $\mathrm{al}^{2}$ in 1973. However, $K_{1}^{\text {inh }}$ is here considered constant, whereas Voltz et al. expressed $K_{1}^{\text {inh }}$ as being dependent on the catalyst temperature. Hlaváček and Votruba ${ }^{28}$ also reported $K_{1}^{\text {inh }}$ as a constant. Indeed, the temperature dependencies reported in the literature are generally low, below $10 \mathrm{~kJ} \mathrm{~mol}^{-1}$, which indicates that it likely is not necessary to make $K_{1}^{\text {inh }}$ temperature dependent. ${ }^{27,29}$

The WGS rate expression (R2) is also presented in Table 1. WGS is an equilibrium reaction, and the equilibrium constant $K_{\text {eq2 }}$ was determined according to

$$
K_{\mathrm{eq}_{2}}=e^{-\Delta G^{\ominus} / R T_{s}}
$$

where $\Delta G^{\ominus}$ is the change in standard Gibbs free energy of the system that occurs during the reaction. It is calculated according to

$$
\Delta G^{\ominus}=\Delta H^{\ominus}-T_{s} \Delta S^{\ominus}
$$

The enthalpy and entropy changes were determined using the values of standard enthalpy and standard entropy:

$$
\begin{aligned}
& H-H_{298.15}=A t+B t^{2}+\frac{C t^{3}}{3}+\frac{D t^{4}}{4}-\frac{E}{t}+F-H \\
& S=A \ln (t)+B t+\frac{C t^{2}}{2}+\frac{D t^{3}}{3}-\frac{E}{2 t^{2}}+G
\end{aligned}
$$

where $t=T_{s} / 1000$, and the coefficients were taken from the open NIST Chemistry WebBook. ${ }^{30}$

3.2.2. $\mathrm{C}_{2} \mathrm{H}_{4}$ Abatement Reactions. The kinetic rate expression for ethylene is drastically different from the classical Langmuir-Hinshelwood structured rate equation. The rate of reaction varies with the $\mathrm{O}_{2} / \mathrm{HC}$ ratio and reaction temperature. Figure 3 shows the ethylene light-off curves as a function of the feed temperature using different lambda conditions from 0.85 to 1.15. At low temperatures (below $225{ }^{\circ} \mathrm{C}$ ), the light-off showed a nearly similar conversion profile when the oxygen feed concentration was varied. This is indeed characteristic of a zero-order reaction with respect to $\mathrm{O}_{2}$ and first-order reaction with respect to $\mathrm{C}_{2} \mathrm{H}_{4}{ }^{31}$ As the feed temperature increases (above $225^{\circ} \mathrm{C}$ ), the light-off curves separate such that higher $\mathrm{O}_{2}$ feed concentrations lead to lower conversions. This is because ethylene adsorbs more weakly than oxygen on $\mathrm{Pd}$ sites, which results in oxygen being the most abundant species on the catalyst surface. ${ }^{32}$ This inhibition effect on $\mathrm{C}_{2} \mathrm{H}_{4}$ 


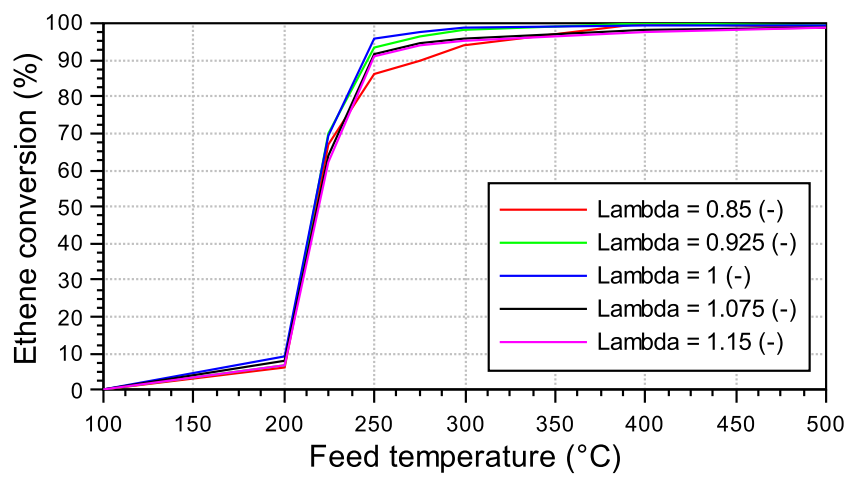

Figure 3. Ethylene conversion as a function of the feed temperature under different lambda conditions.

conversion increases, as the feed becomes leaner. Ethylene indeed reaches full conversion only for slightly rich mixtures $(\lambda$ $=0.925)$, since oxygen is removed from the catalyst surface. As oxygen is removed further, $\mathrm{C}_{2} \mathrm{H}_{4}$ conversion decreases, since there is not enough $\mathrm{O}_{2}$ to enable the complete oxidation. Therefore, at high temperatures, the oxidation kinetics appear to vary with the $\mathrm{O}_{2} / \mathrm{HC}$ ratio. The reaction order switches from positive to negative with respect to oxygen, as the feed becomes leaner; i.e., as the oxygen concentration (lambda) is increased, conversion initially increases but then decreases. In contrast, the oxidation kinetics appear to be zero order with respect to $\mathrm{C}_{2} \mathrm{H}_{4}$ independent of the feed concentration at feed temperatures above $225{ }^{\circ} \mathrm{C}$.

Based on the above discussion, a kinetic rate expression for $\mathrm{C}_{2} \mathrm{H}_{4}$ oxidation has been proposed in this work. This expression is presented in Table $2-$ R3. A similar rate

Table 2. Reactions and Rate Expressions for $\mathrm{C}_{2} \mathrm{H}_{4}$ Oxidation and Steam Reforming Reactions

\begin{tabular}{|c|c|c|}
\hline & reaction & kinetic rate expression \\
\hline \multirow{2}{*}{ (R3) } & \multirow{2}{*}{$\begin{array}{l}\mathrm{C}_{2} \mathrm{H}_{4}+3 \mathrm{O}_{2} \rightarrow 2 \mathrm{CO}_{2}+ \\
\quad 2 \mathrm{H}_{2} \mathrm{O}\end{array}$} & $\mathrm{Pd}_{\text {site }} \frac{k_{3}}{\left(1+K_{3}^{\text {inh }} \mathrm{y}_{\mathrm{O}_{2}}\right)^{2}} y_{\mathrm{C}_{2} \mathrm{H}_{4}} y_{\mathrm{O}_{2}}$ \\
\hline & & 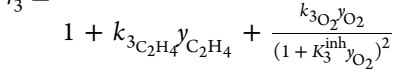 \\
\hline \multirow[t]{2}{*}{ (R4) } & \multirow{2}{*}{$\underset{2}{\mathrm{C}_{2} \mathrm{H}_{4}}+2 \mathrm{H}_{2} \mathrm{O} \leftrightharpoons 2 \mathrm{CO}+$} & $\mathrm{Pd}_{\text {site }} k_{4 \mathrm{f}}\left(y_{\mathrm{C}_{2} \mathrm{H}_{4}} y_{\mathrm{H}_{2} \mathrm{O}}{ }^{2}-\frac{\left.y_{\mathrm{CO}^{2} y_{\mathrm{H}_{2}}{ }^{4}}^{\mathrm{K}_{\mathrm{eq}_{4}}}\right)}{}\right.$ \\
\hline & & 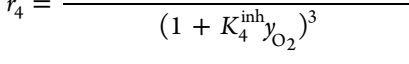 \\
\hline
\end{tabular}

expression was also proposed by Lang et al. ${ }^{32}$ This reaction rate expression can be written as

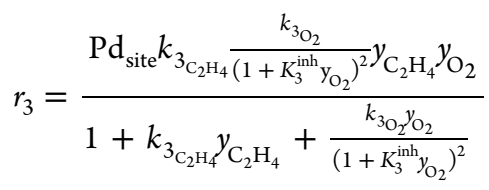

where the rate constants, $k_{3 \mathrm{C}_{2} \mathrm{H}_{4}}$ and $k_{3 \mathrm{O} 2}$, can be combined into a single rate constant $k_{3}$. At low temperatures, $\frac{k_{3_{2} \mathrm{O}_{2}} y_{\mathrm{O}_{2}}}{\left(1+K_{3}^{\text {inh }} y_{\mathrm{O}_{2}}\right)^{2}} \gg 1+k_{3_{\mathrm{C}_{2} \mathrm{H}_{4}}} y_{\mathrm{C}_{2} \mathrm{H}_{4}}, \mathrm{R} 3$ therefore becomes

$$
r_{3}=P d_{\text {site }} k_{3_{\mathrm{C}_{2} \mathrm{H}}{ }_{\mathrm{C}_{2} \mathrm{H}_{4}}}
$$

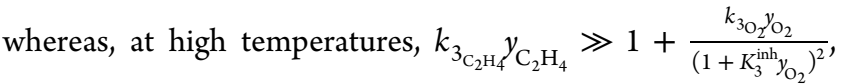
then $\mathrm{R} 3$ is

$$
r_{3}=\operatorname{Pd}_{\text {site }} \frac{k_{3_{\mathrm{O}_{2}}} y_{\mathrm{O}_{2}}}{\left(1+K_{3}^{\mathrm{inh}} y_{\mathrm{O}_{2}}\right)^{2}}
$$

Under this regime (at high temperatures), if $K_{3}^{\mathrm{inh}} y_{\mathrm{O} 2} \gg 1$ (lean conditions), the expression becomes

$$
r_{3}=\mathrm{Pd}_{\text {site }} \frac{k_{3_{\mathrm{O}_{2}}}}{\left(K_{3}^{\text {inh }}\right)^{2}} \frac{1}{y_{\mathrm{O}_{2}}}
$$

It is important to mention that $K_{3}^{\text {inh }}$ is defined in this work as being temperature dependent following the Arrhenius equation. In contrast, if $K_{3}^{\text {inh }} y_{\mathrm{O} 2} \ll 1$ (rich conditions), the expression becomes

$$
r_{3}=\mathrm{Pd}_{\text {site }} k_{3_{\mathrm{O}_{2}}} y_{\mathrm{O}_{2}}
$$

The exquisite sensitivity of ethylene to $\lambda$ at high temperatures also arises from the competition between oxidation and steam reforming (SR) reactions. Similar to the WGS reaction, $\mathrm{SR}$ is an equilibrium reaction presented in Table $2-\mathrm{R} 4$. According to the experimental results, negligible net $\mathrm{CO}$ levels were detected under lean experimental conditions, indicating that the SR reaction is completely inhibited by high concentrations of oxygen. This is probably because active site pairs generated by $\mathrm{H}_{2} \mathrm{O}$ activation $(*, * \mathrm{O})$ are extinguished under $\mathrm{O}_{2}$ excess conditions. ${ }^{33}$ Oxygen will particularly serve to form less active pairs $\left(* \mathrm{O},{ }^{*} \mathrm{O}\right)$, which results in an apparent inhibition of the SR reaction. ${ }^{33}$ This observation has been well expressed in the reaction rate of this work by introducing an inhibition term in the denominator, which depends on the $\mathrm{O}_{2}$ concentration.

3.2.3. $\mathrm{C}_{7} \mathrm{H}_{8}$ Abatement Reactions. The reaction rate expressions for toluene are presented in Table 3, which

Table 3. Reactions and Rate Expressions for $\mathrm{C}_{7} \mathrm{H}_{8}$ Oxidation and Steam Reforming Reactions

$$
\begin{array}{cc}
\text { reaction } & \text { kinetic rate expression } \\
\text { (R5) } \quad \mathrm{C}_{7} \mathrm{H}_{8}+9 \mathrm{O}_{2} \rightarrow 7 \mathrm{CO}_{2}+\quad r_{5} & =\frac{\mathrm{Pd}_{\text {site }_{5}} k_{5} y_{\mathrm{C}_{7} \mathrm{H}_{8}} y_{\mathrm{O}_{2}}}{\left(1+\mathrm{K}_{5}^{\mathrm{inh}} y_{\mathrm{C}_{7} \mathrm{H}_{8}}\right)^{2}} \\
& \mathrm{C}_{7} \mathrm{H}_{8}+7 \mathrm{H}_{2} \mathrm{O} \leftrightharpoons 7 \mathrm{CO}+\quad \mathrm{r}_{6}=\frac{\mathrm{Pd}_{\text {site }} k_{6 \mathrm{f}}\left(y_{\mathrm{C}_{7} \mathrm{H}_{8}} y_{\mathrm{H}_{2} \mathrm{O}}{ }^{7}-\frac{y_{\mathrm{CO}^{7} y_{\mathrm{H}_{2}}}{ }^{11}}{\mathrm{~K}_{\mathrm{eq}_{6}}}\right)}{1+\mathrm{K}_{6}^{\mathrm{inh}} y_{\mathrm{O}_{2}}}
\end{array}
$$

involves the $\mathrm{C}_{7} \mathrm{H}_{8}$ oxidation (R5) and steam reforming (R6) reactions. First, the $\mathrm{C}_{7} \mathrm{H}_{8}$ oxidation expression was taken in accordance with the Langmuir-Hinshelwood structured rate equation, where $y_{\mathrm{O} 2}$ and $y_{\mathrm{C} 7 \mathrm{H} 8}$ are the mole fractions of oxygen and toluene, respectively, and $k_{5}$ is the rate constant of the forward reaction. The term $\left(1+K_{5}^{\text {inh }} y_{\mathrm{C} 7 \mathrm{H} 8}\right)^{2}$ accounts for the inhibition effect by the chemisorption of $\mathrm{C}_{7} \mathrm{H}_{8}$, where $K_{5}^{\text {inh }}$ represents the inhibition factor. On the other hand, the SR reaction of toluene is an equilibrium reaction with the equilibrium constant $K_{\text {eq6. }}$. As with ethylene, this reaction is inhibited under lean conditions, and thus, an inhibition term $\left(1+K_{6}^{\mathrm{inh}} y_{\mathrm{O} 2}\right)$ dependent on the $\mathrm{O}_{2}$ concentration was introduced in the denominator of the equation.

3.2.4. Oxygen Storage Reactions. Considering the complicated formulation of a TWC catalyst and strong interactions among ceria, zirconia, and palladium site elements, it is challenging to distinguish the contribution of each of them 
to the overall oxygen storage. Moreover, it was found by $\mathrm{Yao}^{34}$ that the amount of oxygen stored on precious metals is much smaller compared to that on ceria. Thus, the oxygen storage on precious metals and ceria sites was combined together in this work. Table $4 \mathrm{R} 7$ shows the reaction rate expression for the

\section{Table 4. Ceria Reactions and Rate Expressions}

\begin{tabular}{lll} 
& \multicolumn{1}{c}{ reaction } & kinetic rate expression \\
$(\mathrm{R} 7)$ & $\mathrm{Ce}_{2} \mathrm{O}_{3}+0.5 \mathrm{O}_{2} \rightarrow 2 \mathrm{CeO}_{2}$ & $r_{7}=\mathrm{Ce}_{\text {site }} k_{7} y_{\mathrm{O} 2}(1-\theta)$ \\
$(\mathrm{R} 8)$ & $\mathrm{CO}+2 \mathrm{CeO}_{2} \rightarrow \mathrm{Ce}_{2} \mathrm{O}_{3}+\mathrm{CO}_{2}$ & $r_{8}=\mathrm{Ce}_{\text {site }} k_{8} y_{\mathrm{CO}} \theta$ \\
$(\mathrm{R} 9)$ & $\mathrm{H}_{2}+2 \mathrm{CeO}_{2} \rightarrow \mathrm{Ce}_{2} \mathrm{O}_{3}+\mathrm{H}_{2} \mathrm{O}$ & $r_{9}=\mathrm{Ce}_{\text {site }} k_{9} y_{\mathrm{H} 2} \theta$ \\
\hline
\end{tabular}

oxygen storage. The coverage parameter, $\theta$, is defined as the ratio between the oxygen storage component in the higher oxidation state (more stable) and the total occupied oxygen storage sites, as presented below:

$$
\theta=\frac{\text { moles of } \mathrm{CeO}_{2}}{\text { moles of } \mathrm{CeO}_{2}+2 \text { moles of } \mathrm{Ce}_{2} \mathrm{O}_{3}}
$$

During rich operation, $\mathrm{H}_{2}$ and $\mathrm{CO}$ are the most reactive species to deplete the stored $\mathrm{O}_{2} \cdot{ }^{35}$ Thus, kinetics of oxygen storage capacity depletion by $\mathrm{H}_{2}$ and $\mathrm{CO}$ must be considered in our model. These expressions are also presented in Table 4 (reactions R8 and R9). It should be mentioned that R8 and R9 reactions are usually reversible. Since the reverse reaction rates generally become important at temperatures above $500{ }^{\circ} \mathrm{C},{ }^{35}$ we have neglected the reverse reaction in the present work.

3.2.5. Hydrogen Oxidation. Hydrogen produced in the WGS and SR reactions can be also oxidized into $\mathrm{H}_{2} \mathrm{O}$. It was assumed that the surface reaction of adsorbed $\mathrm{H}_{2}$ and adsorbed $\mathrm{O}$ takes place on palladium sites. This assumption is consistent with earlier publication that $\mathrm{H}_{2}$ oxidation proceeds on the metallic sites. ${ }^{36}$ The kinetic rate expression used is presented in Table 5 (R10).

Table 5. $\mathrm{H}_{2}$ Oxidation Reaction and Rate Expression

$\begin{array}{ccc} & \text { reaction } & \text { kinetic rate expression } \\ (\mathrm{R} 10) & \mathrm{H}_{2}+0.5 \mathrm{O}_{2} \rightarrow \mathrm{H}_{2} \mathrm{O} & r_{10}=\mathrm{Pd}_{\mathrm{site}} k_{10} y_{\mathrm{H} 2} y_{\mathrm{O} 2}\end{array}$

\section{RESULTS AND DISCUSSION}

4.1. Catalyst Characterization. The average Pd particle size was calculated from STEM images, as presented in Figure 4. The average $\mathrm{Pd}$ particle size was $24.7 \mathrm{~nm}$, which resulted from the measurement of 57 different particles. The calculation was performed assuming that the precious metals had spherical shapes and were equally distributed over the support, using the following formula:

$$
d_{D}=2 \sqrt{\frac{A_{p}}{\pi}}
$$

$A_{p}$ represents the area of the particle, and $d_{D}$ is the particle diameter. Based on the particle size, the precious metal dispersion was derived using the following relation: ${ }^{37}$

$$
D=\frac{1.11}{d_{D}}
$$

where $D$ is the precious metal dispersion $(0<D<1)$ and $d_{D}$ is given in nanometers. This calculation resulted in a dispersion of $4.5 \%$. Moreover, the specific surface area from the BET measurements resulted in $90.4 \mathrm{~m}^{2} / \mathrm{g}$.

Furthermore, the coated GPF sample was divided into sections, and the cross-sectioned areas of the filter walls were examined by SEM-EDX, as presented in Figure 5. Support elements of aluminum, cerium, and zirconium appeared to penetrate deep into the filter wall with a homogeneous distribution over the whole porous substrate material. This means that the entire monolith is catalytically active, and reactions are not restricted to certain regions within the geometry. Note that the filter substrate also contains Al.

4.2. Kinetic Parameter Estimation with the Clean Filter. Figure 6 shows the experimental and simulated outlet concentrations of $\mathrm{CO}, \mathrm{C}_{2} \mathrm{H}_{4}$, and $\mathrm{C}_{7} \mathrm{H}_{8}$ for the soot-free catalyst under different feed temperatures and lambda conditions. A magnification of the outlet concentrations of $\mathrm{C}_{2} \mathrm{H}_{4}$ with a soot-free catalyst under different feed temperatures and lambda conditions is presented in Figure S1 in the Supporting Information (SI). Note that the conversion efficiencies of $\mathrm{CO}, \mathrm{C}_{2} \mathrm{H}_{4}$, and $\mathrm{C}_{7} \mathrm{H}_{8}$ with soot-free and sootloaded samples are shown in our previous publication. ${ }^{21}$ The kinetic parameters for the model are given in Table 6 and the
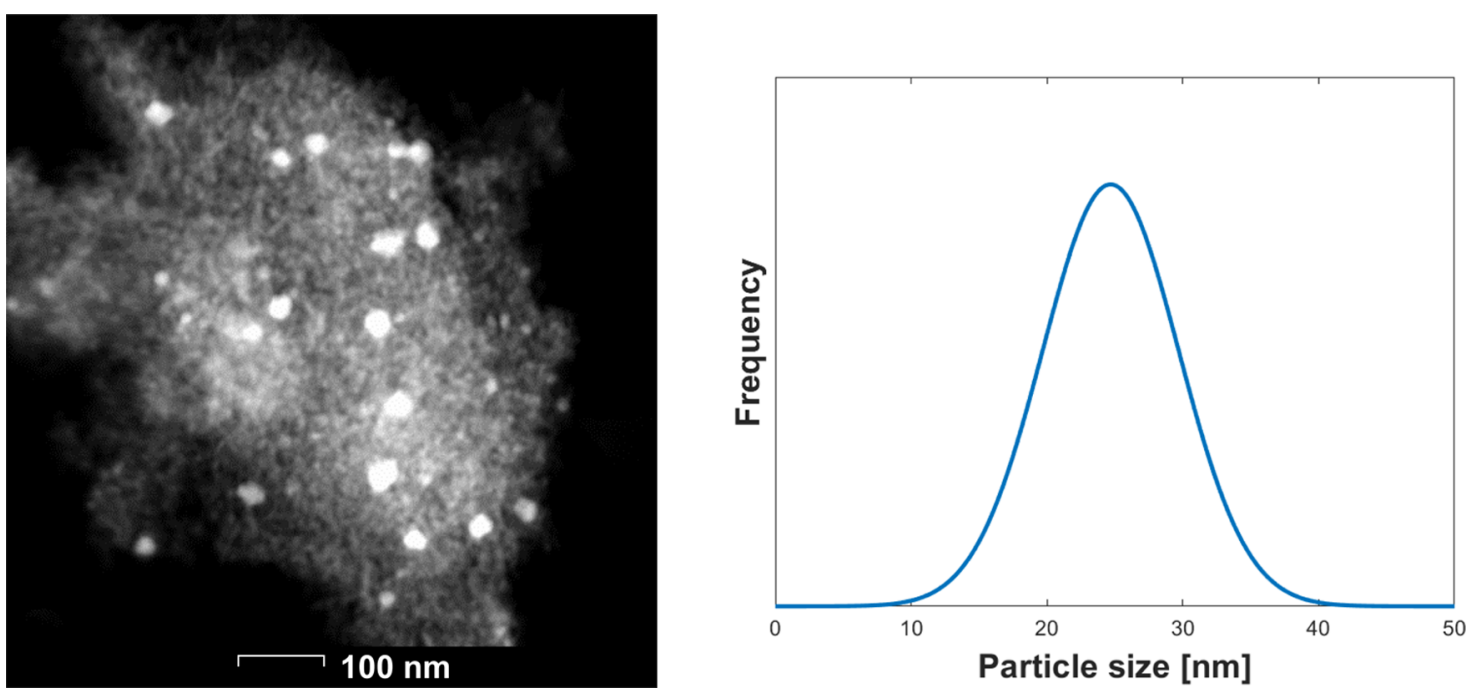

Figure 4. STEM image (left) and the particle size distribution (right) determined from the measurement of $57 \mathrm{Pd}$ particles. 

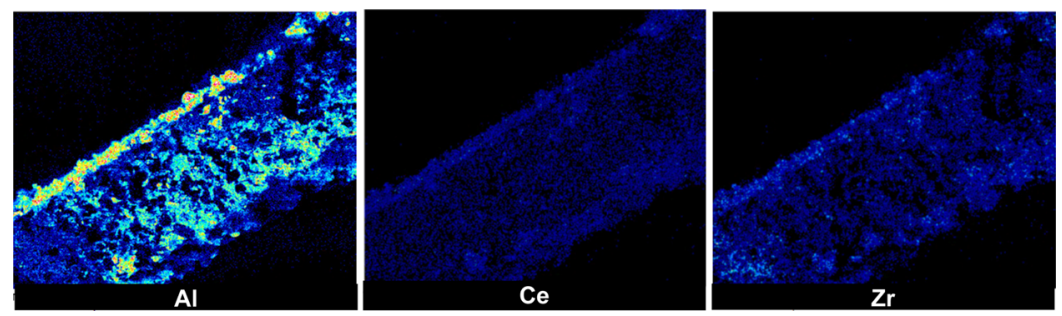

Figure 5. SEM-EDX mapping of the catalyst distribution within the filter wall.
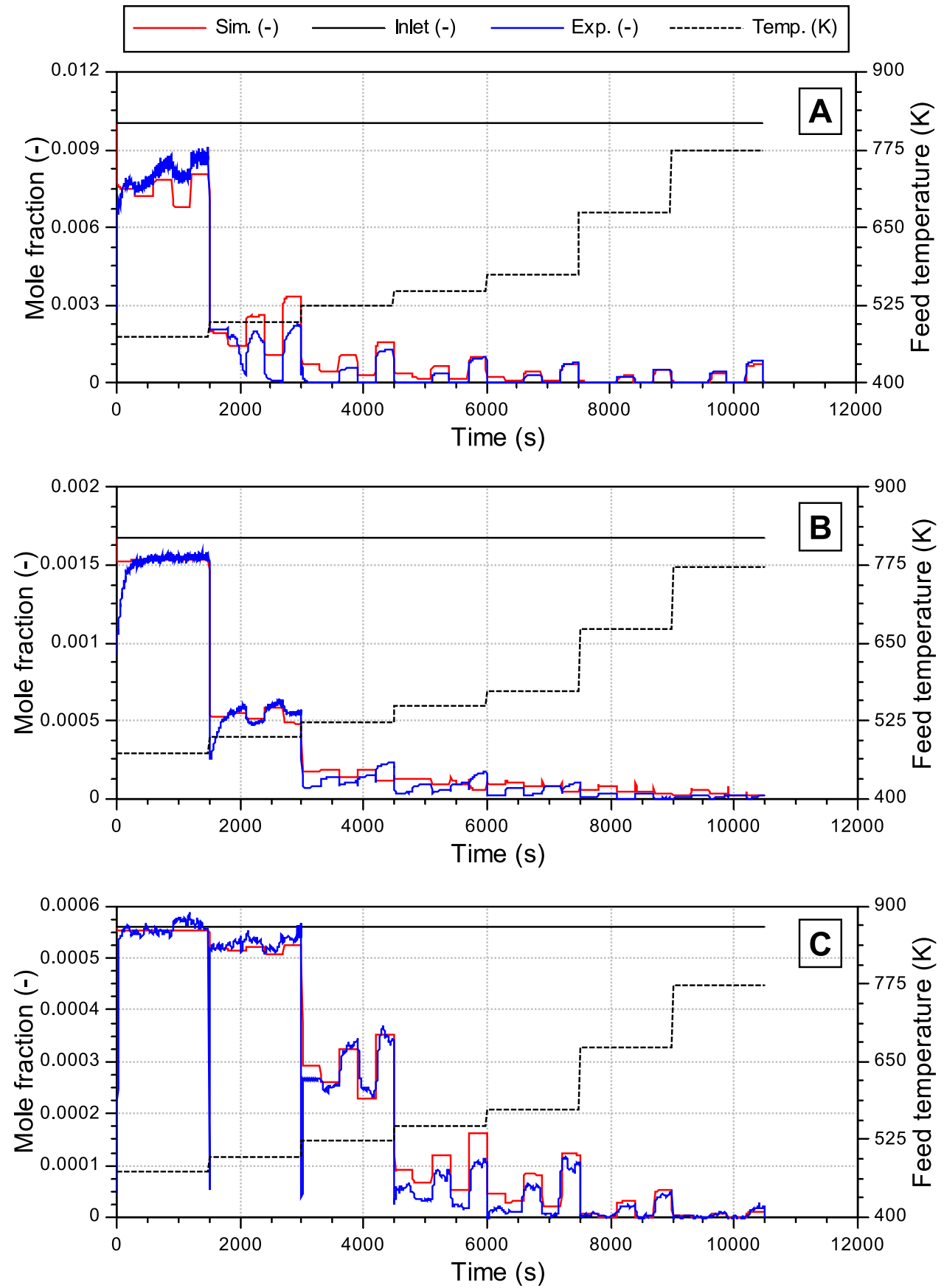

Figure 6. Outlet concentrations of $(A) \mathrm{CO},(B) \mathrm{C}_{2} \mathrm{H}_{4}$, and (C) $\mathrm{C}_{7} \mathrm{H}_{8}$ with a soot-free catalyst under different feed temperatures and lambda conditions. The experimental results are presented with solid blue lines, while the simulation results are shown with solid red lines. The inlet $\mathrm{CO} /$ $\mathrm{HC}$ concentrations are given in Figure 2. In addition, $\mathrm{O}_{2}$ (variable), $\mathrm{CO}_{2}(12 \%)$, and $\mathrm{H}_{2} \mathrm{O}(5 \%)$ were present.

additional parameters in Table S1 (Supporting Information). The kinetic parameters were initially manually tuned using the commercial software AVL BOOST. The manual tuning consisted of fitting first the kinetic parameters to the 


\section{Table 6. Kinetic Parameters}

$\begin{array}{cccc}\text { reaction } & \begin{array}{c}\text { enthalpy of reaction } \\ (\mathrm{kJ} / \mathrm{mol})\end{array} & \begin{array}{c}\text { pre-exponential } \\ \text { factor }\left(\mathrm{s}^{-1}\right)\end{array} & \begin{array}{c}\text { activation energy } \\ (\mathrm{kJ} / \mathrm{mol})\end{array} \\ \text { R1 } & -283 & 8 \times 10^{15} & 93.0 \\ \text { R2 } & -41.2 & 3 \times 10^{12} & 85.0 \\ \text { R3 } & -1323 & 2.5 \times 10^{24} & 163.1 \\ \text { R4 } & 210 & 3 \times 10^{18} & 105.7 \\ \text { R5 } & -3771.9 & 2.6 \times 10^{19} & 138.9 \\ \text { R6 } & 868.9 & 6.5 \times 10^{19} & 97.3 \\ \text { R7 } & -100 & 5 \times 10^{7} & 62.0 \\ \text { R8 } & -183 & 5 \times 10^{5} & 40.0 \\ \text { R9 } & -142 & 1 \times 10^{4} & 35.0 \\ \text { R10 } & -242 & 6.5 \times 10^{15} & 90.0\end{array}$

experimental results of the oxidation reactions under lean conditions, since under this regime, WGS and SR reactions were inhibited. Thereafter, WGS and SR parameters were tuned under rich conditions. After the manual tuning, the optimization of the parameters was also carried out with the software AVL Design Explorer using the Genetic Algorithm method.

The model is able to describe adequately the experimental results for all three reductants over a broad range of operating conditions. The estimated kinetic parameters appeared to be in agreement to those presented in the literature. For instance, the activation energy of $\mathrm{CO}$ was estimated at $93 \mathrm{~kJ} / \mathrm{mol}$ for the so-called monofunctional path (reaction on the precious
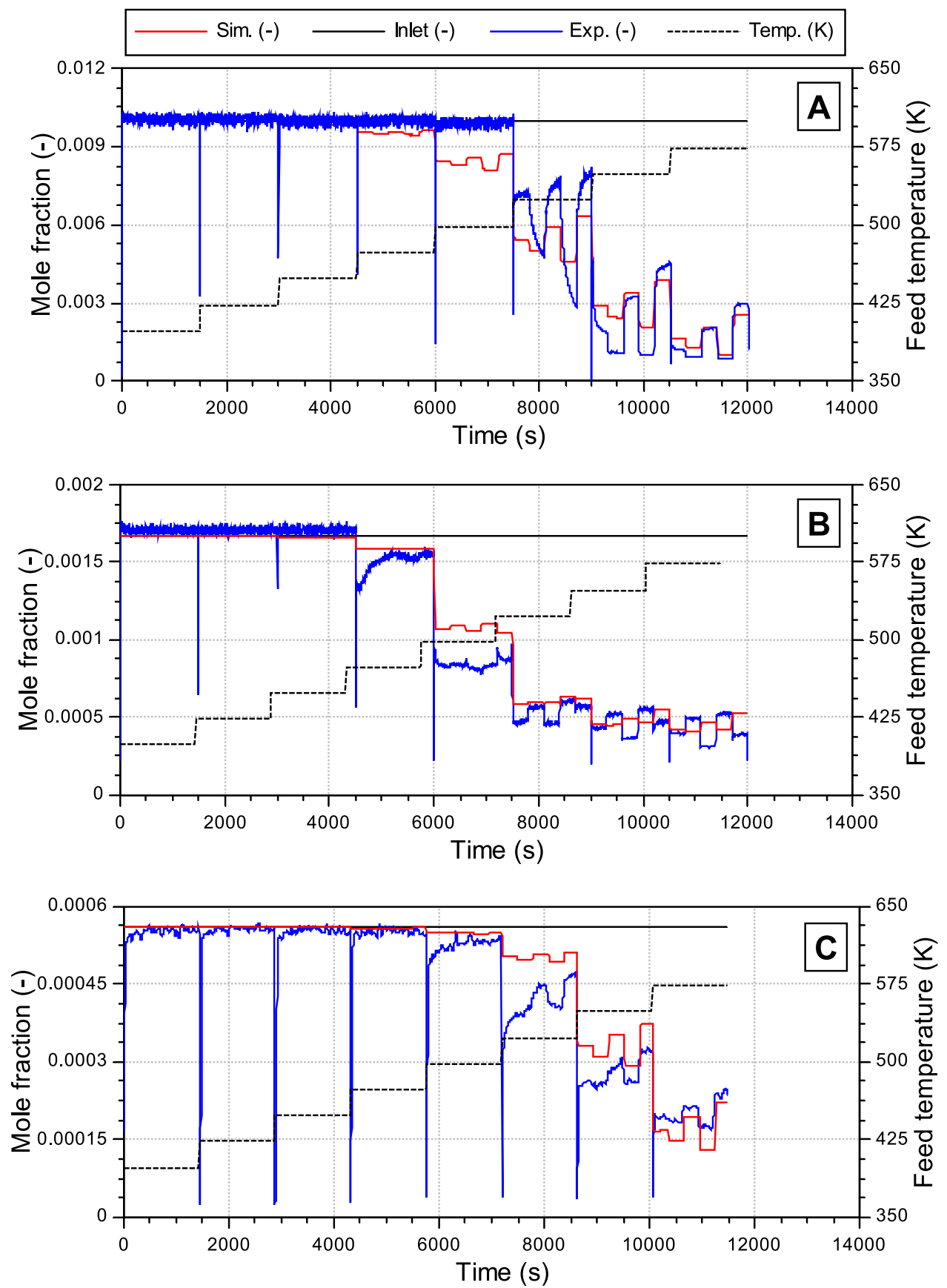

Figure 7. Outlet concentrations of (A) $\mathrm{CO},(B) \mathrm{C}_{2} \mathrm{H}_{4}$, and (C) $\mathrm{C}_{7} \mathrm{H}_{8}$ with a soot-loaded catalyst under different feed temperatures and lambda conditions. The experimental results are presented with solid blue lines, while the simulation results are shown with solid red lines. 
metals only), while it is presented in the literature in a range from 88 to $122 \mathrm{~kJ} / \mathrm{mol}^{1,9,38}$ for TWC. This activation energy is generally close to the binding energy of absorbed CO. ${ }^{39}$ This is because the catalyst surface is almost completely covered by $\mathrm{CO}$ under reaction conditions, and hence, the reaction rate is controlled by the rate of $\mathrm{CO}$ desorption. Oxygen can only adsorb at precious metal sites where $\mathrm{CO}$ has desorbed, resulting in first-order dependence in $\mathrm{O}_{2}$ and negative firstorder dependence in $\mathrm{CO}$, as presented in the reaction expression R1 (see Table 1). Further CO conversion was achieved with the so-called bifunctional path in which the reaction takes place at the noble metal/ceria interface. ${ }^{40}$ This path first involves the oxygen adsorption on ceria sites (R7) under $\mathrm{O}_{2}$ excess conditions, which was estimated with an activation energy of $62 \mathrm{~kJ} / \mathrm{mol}$ in the present work, in line with some other studies where $67 \mathrm{~kJ} / \mathrm{mol}$ was found. ${ }^{41}$ Thereafter, ceria is reduced by $\mathrm{CO}$ and $\mathrm{H}_{2}$ under conditions of low oxygen concentrations. Both reactions were estimated with activation energies of 40 and $35 \mathrm{~kJ} / \mathrm{mol}$. Furthermore, the WGS reaction also contributed to $\mathrm{CO}$ conversion. The estimated activation energy of the WGS also agrees with the literature. Shwan et al. $^{42}$ reported $76 \mathrm{~kJ} / \mathrm{mol}$ for an $\mathrm{NO}_{X}$ storage and reduction catalyst, and Han et al. ${ }^{43}$ calculated apparent activation energies of 76.7 and $169.8 \mathrm{~kJ} / \mathrm{mol}$ for a fresh and aged $\mathrm{Pd} /$ $\mathrm{Ce}_{0.67} \mathrm{Zr}_{0.33} \mathrm{O}_{2} / \mathrm{Al}_{2} \mathrm{O}_{3}$ catalyst, similar to the sample synthesized in this study.

The model also predicted the $\mathrm{C}_{2} \mathrm{H}_{4}$ conversion very well over the broad range of temperatures and feed $\mathrm{O}_{2}$ concentrations. In particular, the inhibition effect of oxygen was adequately captured by the model under high $\mathrm{O}_{2}$ feed concentrations. Note that the estimated overall activation energy was high at $163.1 \mathrm{~kJ} / \mathrm{mol}$. In fact, studies have reported a wide range of activation energies, between 40 and $200 \mathrm{~kJ} /$ mol, mostly depending on the type of ethylene surface species formed. ${ }^{44-50}$ There are two types of surface species: $\pi$-bonded ethylene, which is oxidized very fast, and di- $\sigma$ ethylene, which is oxidized much more slowly. ${ }^{48} \pi$-Bonded ethylene is adsorbed on one single precious metal site, while di- $\sigma$ ethylene is adsorbed on two active sites (more stable). ${ }^{48}$ This is in agreement with the binding energies reported in the literature, where di- $\sigma$ ethylene is in a range from 131 to $200 \mathrm{~kJ} / \mathrm{mol}^{45-47}$ while $\pi$-bonded ethylene has been assigned from 40 to $54 \mathrm{~kJ} /$ mol. ${ }^{44,51}$ It is therefore reasonable to assume, based on the high activation energy obtained, that the principal adsorption mode for $\mathrm{C}_{2} \mathrm{H}_{4}$ in the present work is di- $\sigma$ ethylene. The formation of di- $\sigma$ bonding is usually accompanied by the formation of several products, such as ethylidyne and methylidyne groups, vinyl species, etc. ${ }^{51}$ The formation of these species depends on the temperature and surface coverage. $^{51}$ In addition, SR was also considered for $\mathrm{C}_{2} \mathrm{H}_{4}$ conversion under rich conditions. The activation energy was estimated to be $105.8 \mathrm{~kJ} / \mathrm{mol}$, whereas the inhibition factor was computed based on the Arrhenius equation $\left(A_{4}^{\mathrm{inh}}, E_{4}^{\mathrm{inh}}\right)$ defined above.

The kinetic model was also able to describe satisfactorily the experimental results for toluene conversion, as presented in Figure $6 \mathrm{C}$. The activation energies for the oxidation and for the $S R$ reactions were estimated to be 138.9 and $97.3 \mathrm{~kJ} / \mathrm{mol}$, respectively. In particular, the toluene oxidation was between $106 \mathrm{~kJ} / \mathrm{mol}$ calculated by Ordóñez et al. ${ }^{52}$ and $161 \mathrm{~kJ} / \mathrm{mol}$ reported by Morales-Torres et al. ${ }^{53}$ for the oxidation of toluene on palladium catalysts supported on carbon nanofibers. Similar to $\mathrm{CO}$ oxidation, toluene oxidation is strongly dependent on
$\mathrm{O}_{2}$ concentration and inhibited by the strong adsorption of the unsaturated hydrocarbon on the Pd surface by $\pi$-bonds. ${ }^{34}$ This strong interaction of the hydrocarbon with the catalyst surface is explained by the fact that the methyl group in the $\mathrm{C}_{7} \mathrm{H}_{8}$ structure raises the electronic density of the aromatic ring, making the interaction between the catalyst surface and the molecule stronger. ${ }^{52}$ Therefore, at high $\mathrm{C}_{7} \mathrm{H}_{8}$ concentrations, the catalyst surface is almost completely covered by toluene, and the reaction rate is determined by the surface concentration of oxygen. In contrast, at low toluene concentrations, toluene oxidation is faster and the hydrocarbon surface concentration is the controlling factor.

4.3. Soot Inhibition Effect on TWC Reactions. According to our previously published study, ${ }^{21}$ the TWC reactions of cGPFs were affected in the presence of soot. Sootloaded samples presented lower conversion efficiencies with respect to soot-free cGPFs, indicating that part of the active sites were masked by the accumulation of soot on the filter. This masking effect blocks or limits the access of reactants to the active sites, inhibiting the gaseous pollutant conversion. This is well documented in the literature. ${ }^{54,55}$ Thus, this inhibition effect was simulated in this study over the $\mathrm{Pd} / \mathrm{CeZr} /$ $\mathrm{Al}_{2} \mathrm{O}_{3}$ sample using the reaction expressions and kinetic parameters estimated above, with the purpose of understanding the kinetic processes taking place in the presence of soot over the whole range of operating conditions. Compared to soot-free experiments, the feed temperature was limited between 125 and $300{ }^{\circ} \mathrm{C}$ to prevent the soot oxidation, whereas $\lambda$-values were kept the same, ranging from 0.85 to 1.15 .

Figure 7 shows the experimental and simulated outlet concentrations of $\mathrm{CO}, \mathrm{C}_{2} \mathrm{H}_{4}$, and $\mathrm{C}_{7} \mathrm{H}_{8}$ for the soot-loaded catalyst. In this case, the inhibition of soot was simulated through the reduction of palladium and ceria site density (both with the same proportion), according to Table 7. This

Table 7. Site Density Reduction for $\mathrm{CO}, \mathrm{C}_{2} \mathrm{H}_{4}$, and $\mathrm{C}_{7} \mathrm{H}_{8}$ because of the Soot Inhibition Effect

$\begin{array}{lc}\text { species } & \text { site density reduction (\%) } \\ \mathrm{CO} & 77 \\ \mathrm{C}_{2} \mathrm{H}_{4} & 31 \\ \mathrm{C}_{7} \mathrm{H}_{8} & 72\end{array}$

reduction in site density was carried out to fit the simulated results to the experimental data. The kinetic parameters estimated with the clean filter were kept constant. These results clearly show that ethylene seems to be less affected by the presence of soot compared to $\mathrm{CO}$ and toluene. The latter species presented similar results with a reduction of active site density of around $75 \%$, whereas the reduction was only $31 \%$ for $\mathrm{C}_{2} \mathrm{H}_{4}$. This observation is probably related to the type of surface species formed. As mentioned above, $\mathrm{CO}$ and toluene share similar chemisorption behavior with a strong adsorption on a single active site through $\pi$-bonds. ${ }^{34}$ In contrast, ethylene may adsorb on sites, covered with oxygen, with the primary adsorption mode of di- $\sigma$ bonding. Di- $\sigma$ bonding can be initially formed from $\pi$-bonded species ${ }^{48}$ and can be then also accompanied by the formation of other more stable and less reactive products. This is only possible when a large number of vacant sites are available at the catalyst surface. ${ }^{48}$ It is therefore reasonable to assume that the accumulation of soot on the filter reduced the number of active sites on the catalyst surface, 


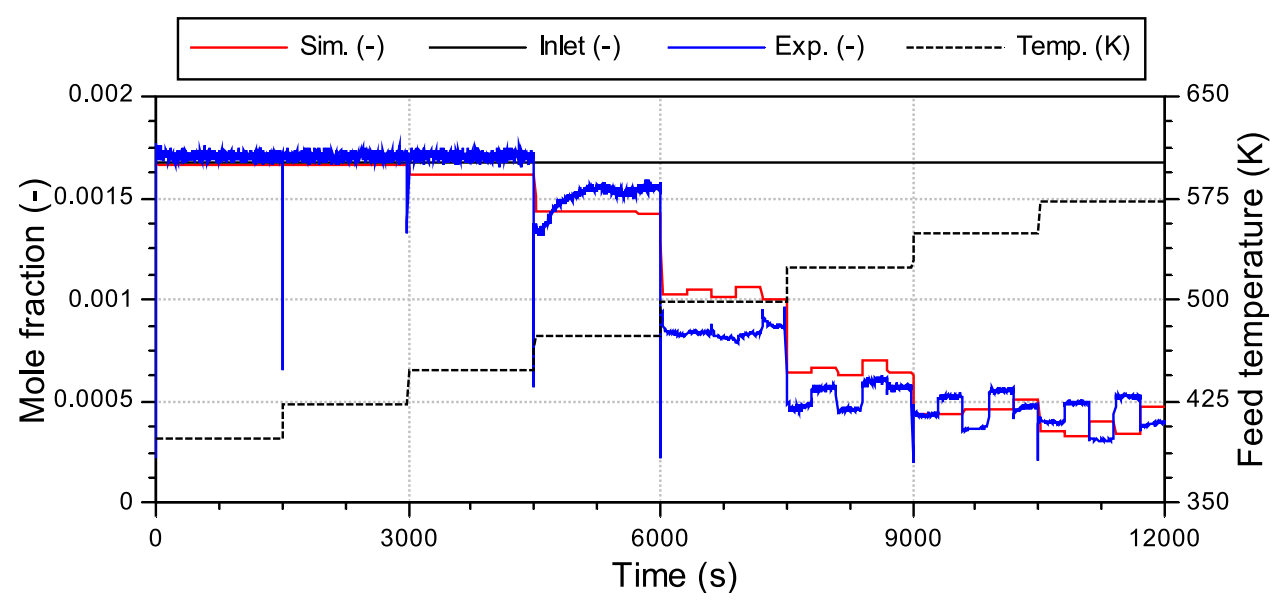

Figure 8. Simulated and experimental outlet concentrations of $\mathrm{C}_{2} \mathrm{H}_{4}$ for the soot-loaded catalyst under different feed temperatures and lambda conditions. The kinetic parameters have been modified with respect to the soot-free parameters, with a site density reduction of $75 \%$.

inhibiting the formation of more stable $\mathrm{C}_{2} \mathrm{H}_{4}$ species. Instead, more reactive species, like $\pi$-bonded species, were probably formed due to the lack of vacant sites, resulting in a lower soot inhibition effect over $\mathrm{C}_{2} \mathrm{H}_{4}$ compared to $\mathrm{CO}$ and toluene.

This observation therefore indicates that the kinetic parameters of $\mathrm{C}_{2} \mathrm{H}_{4}$ varied in the presence of soot. Using the same number of active site reductions as with $\mathrm{CO}$ and toluene, the kinetic parameters of $\mathrm{C}_{2} \mathrm{H}_{4}$ oxidation were adjusted to corroborate the formation of more reactive species. Figure 8 shows the simulated and experimental outlet concentrations of $\mathrm{C}_{2} \mathrm{H}_{4}$ for the soot-loaded catalyst with a site density reduction of $75 \%$, and the adjusted kinetic parameters are given in Table 8. The activation energy of the ethylene oxidation reaction was

\section{Table 8. Kinetic Parameters for $\mathrm{C}_{2} \mathrm{H}_{4}$ Oxidation for the} Soot-Loaded Sample

\begin{tabular}{ll}
\multicolumn{1}{c}{ parameters } & \multicolumn{1}{c}{ value } \\
site density reduction & $75 \%$ \\
pre-exponential factor of $k_{3}$ & $3.1 \times 10^{19}\left(\mathrm{~s}^{-1}\right)$ \\
activation energy of $k_{3}$ & $105,300(\mathrm{~J} / \mathrm{mol})$ \\
pre-exponential factor of $k_{3 \mathrm{O} 2}$ & $7 \times 10^{14}(-)$ \\
activation energy of $k_{3 \mathrm{O} 2}$ & $300(\mathrm{~J} / \mathrm{mol})$ \\
pre-exponential factor of $k_{3 \mathrm{C} 2 \mathrm{H} 4}$ & $44,000(-)$ \\
activation energy of $k_{3 \mathrm{C} 2 \mathrm{H} 4}$ & $105,000(\mathrm{~J} / \mathrm{mol})$
\end{tabular}

significantly decreased from 163 to $105 \mathrm{~kJ} / \mathrm{mol}$ in the presence of soot (see Table 6 and Table 8). This clearly shows the formation of less stable and more reactive species on $\mathrm{Pd}$ sites as the number of vacant sites is reduced by the soot masking effect.

\section{CONCLUSIONS}

A global kinetic model for TWC-coated GPFs was developed in this work to understand the relevant TWC reaction mechanisms and kinetic processes taking place both in clean and soot-loaded filters. Flow-reactor results from our previous publication were here employed to develop reaction rate expressions and to estimate kinetic parameters. The experiments were performed over a model $\mathrm{Pd} / \mathrm{CeZr} / \mathrm{Al}_{2} \mathrm{O}_{3}$ catalyst hydrothermally treated at $650{ }^{\circ} \mathrm{C}$ in which real soot was directly collected from a Volvo gasoline vehicle. Overall, the model is able to describe adequately the experimental results for all three reductants $\left(\mathrm{CO}, \mathrm{C}_{2} \mathrm{H}_{4}\right.$, and $\left.\mathrm{C}_{7} \mathrm{H}_{8}\right)$ over the broad range of feed temperatures and $\mathrm{O}_{2}$ concentrations. In particular, ethylene presented different oxidation trends compared to $\mathrm{CO}$ and toluene. At low temperatures, the reaction order was positive with respect to ethylene and zero order with respect to oxygen, i.e., with no ethylene selfinhibition. At high temperatures, the reaction orders appeared to change to negative order with respect to oxygen and zero order with respect to ethylene. Based on these observations, a kinetic expression for ethylene oxidation was proposed in this work that is able to capture most of the experimental trends observed.

Ethylene also exhibited a different behavior in the presence of soot compared to $\mathrm{CO}$ and toluene. The soot inhibition was modeled through the reduction of the active site density based on the fact that the soot accumulation masks the active sites, limiting or blocking the access of reactants. $\mathrm{CO}$ and $\mathrm{C}_{7} \mathrm{H}_{8}$ presented similar site density reduction, while $\mathrm{C}_{2} \mathrm{H}_{4}$ seemed to be less affected by the presence of soot. This observation may be associated with the formation of less stable and more reactive species on the catalyst surface due to the reduction of vacancies on the catalyst. This effect was corroborated by adjusting the kinetic parameters of $\mathrm{C}_{2} \mathrm{H}_{4}$ using the same number of active sites as used with $\mathrm{CO}$ and toluene, resulting in a substantial reduction of the activation energy required for the ethylene oxidation reaction.

\section{ASSOCIATED CONTENT}

\section{SI Supporting Information}

The Supporting Information is available free of charge at https://pubs.acs.org/doi/10.1021/acs.iecr.1c02742.

Magnification of Figure $6 \mathrm{~b}$ and additional parameters for the model (PDF)

\section{AUTHOR INFORMATION}

\section{Corresponding Author}

Louise Olsson - Chemical Engineering, Competence Centre for Catalysis, Chalmers University of Technology, Gothenburg SE-412 96, Sweden; (1) orcid.org/0000-0002-8308-0784; Email: louise.olsson@chalmers.se

\section{Authors}

Jesus De Abreu Goes - Volvo Cars, Gothenburg SE-405 31, Sweden; Chemical Engineering, Competence Centre for 
Catalysis, Chalmers University of Technology, Gothenburg SE-412 96, Sweden

Timothy C. Watling - Johnson Matthey, Sonning Common, Reading RG4 9NH, U.K.; (1) orcid.org/0000-0003-20506183

Complete contact information is available at:

https://pubs.acs.org/10.1021/acs.iecr.1c02742

\section{Notes}

The authors declare no competing financial interest.

\section{ACKNOWLEDGMENTS}

This study is a collaboration between Johnson Matthey, Volvo Car Corporation, and Competence Centre for Catalysis at Chalmers University of Technology. We gratefully acknowledge the financial support from Volvo Car Corporation and the Swedish Foundation for Strategic Research (ID15-0030).

\section{NOMENCLATURE LIST}

$A_{\text {gis }} \quad$ wall surface area in the inlet channel $\left(\mathrm{m}^{2}\right)$

$A_{\text {gos }} \quad$ wall surface area in the outlet channel $\left(\mathrm{m}^{2}\right)$

$A_{w} \quad$ flow cross section in the wall $\left(\mathrm{m}^{2}\right)$

$A_{j} \quad$ pre-exponential factor for reaction $i\left(\mathrm{~s}^{-1}\right)$

$C e_{\text {site }}$ cerium surface site density $\left(\mathrm{mol} / \mathrm{m}^{3}\right)$

$d_{\text {hyd }}$ hydraulic diameter of the channel $(\mathrm{m})$

$D_{j} \quad$ diffusion coefficient for species $j$

$E_{A i}$ activation energy for reaction $i(\mathrm{~J} / \mathrm{mol})$

$\Delta G \quad$ Gibbs free energy $(\mathrm{J} / \mathrm{mol})$

$\Delta H$ enthalpy change $(\mathrm{J} / \mathrm{mol})$

$K_{\text {eq }}$ equilibrium constant $(-)$

$k_{i} \quad$ rate constant for reaction $i\left(\mathrm{~s}^{-1}\right)$

$m_{\text {gi }} \quad$ mass of the gas phase in the inlet channel $(\mathrm{kg})$

$m_{\text {go }}$ mass of the gas phase in the outlet channel $(\mathrm{kg})$

$\dot{m}_{\text {gis }}$ mass flow from the inlet channel into the wall $(\mathrm{kg} / \mathrm{s})$

$\dot{m}_{\text {gon }}$ mass flow from the wall into the outlet channel $(\mathrm{kg} / \mathrm{s})$

$M G_{j} \quad$ molar mass of gas-phase species $j(\mathrm{~kg} / \mathrm{mol})$

$P d_{\text {site }}$ palladium surface site density $\left(\mathrm{mol} / \mathrm{m}^{3}\right)$

$\dot{r}_{\mathrm{w}, \mathrm{i}}$ reaction rate for reaction $i\left(\mathrm{~mol} / \mathrm{s} / \mathrm{m}^{3}\right.$ volume of monolith)

$R \quad$ gas constant $(\mathrm{J} /(\mathrm{mol} \mathrm{K}))$

$\Delta S$ entropy change $(\mathrm{J} /(\mathrm{mol} \mathrm{K}))$

Sh Sherwood number (-)

$T_{s} \quad$ temperature at the catalyst surface $(\mathrm{K})$

$t$ time $(\mathrm{s})$

$x \quad$ spatial coordinate along the porous filter wall structure (m)

$w_{\mathrm{g}, j} \quad$ mass fraction of species $j(-)$

$y_{j} \quad$ mole fraction of species $j(-)$

$z \quad$ spatial coordinate along the channels $(\mathrm{m})$

\section{Greek letters}

$\beta$ mass transfer coefficient $(\mathrm{m} / \mathrm{s})$

$\nu$ stoichiometry coefficient in the filter wall $(-)$

$\rho$ density $\left(\mathrm{kg} / \mathrm{m}^{3}\right)$

$\theta_{\mathrm{j}}$ coverage parameter $(-)$

$\theta$ coverage parameter for oxygen storage on ceria $(-)$

\section{REFERENCES}

(1) Dubien, C.; Schweich, D.; Mabilon, G.; Martin, B.; Prigent, M. Three-way catalytic converter modelling: fast- and slow-oxidizing hydrocarbons, inhibiting species, and steam-reforming reaction. Chem. Eng. Sci. 1998, 53, 471-481.
(2) Voltz, S. E.; Morgan, C. R.; Liederman, D.; Jacob, S. M. Kinetic Study of Carbon Monoxide and Propylene Oxidation on Platinum Catalysts. Product R\&D 1973, 12, 294-301.

(3) Subramanian, B.; Varma, A. Reaction kinetics on a commercial three-way catalyst: the carbon monoxide-nitrogen monoxide-oxygenwater system. Ind. Eng. Chem. Prod. Des. Dev. 1985, 24, 512-516.

(4) Nibbelke, R. H.; Campman, M. A. J.; Hoebink, J. H. B. J.; Marin, G. B. Kinetic Study of the CO Oxidation over $\mathrm{Pt} / \gamma-\mathrm{Al}_{2} \mathrm{O}_{3}$ and $\mathrm{Pt} / \mathrm{Rh} /$ $\mathrm{CeO}_{2} / \gamma-\mathrm{Al}_{2} \mathrm{O}_{3}$ in the Presence of $\mathrm{H}_{2} \mathrm{O}$ and $\mathrm{CO}_{2}$. J. Catal. 1997, 171, 358-373.

(5) Nibbelke, R. H.; Nievergeld, A. J. L.; Hoebink, J. H. B. J.; Marin, G. B. Development of a transient kinetic model for the $\mathrm{CO}$ oxidation by $\mathrm{O}_{2}$ over a $\mathrm{Pt} / \mathrm{Rh} / \mathrm{CeO}_{2} / \gamma-\mathrm{Al}_{2} \mathrm{O}_{3}$ three-way catalyst. Appl Catal $\mathrm{B}$ 1998, 19, 245-259.

(6) Hauck, C.; Tischer, S.; Maier, L.; Deutschmann, O. Modelling of local aging effects of commercial three-way catalysts: Spatial temperature and CO conversion profiles. Can. J. Chem. Eng. 2014, 92, 1587-1596.

(7) Kang, S. B.; Nam, I.-S.; Cho, B. K.; Kim, C. H.; Oh, S. H. Kinetic model for modern double-layered $\mathrm{Pd} / \mathrm{Rh} \mathrm{TWC}$ as a function of metal loadings and mileage. Chem. Eng. J. 2015, 278, 328-338.

(8) Kang, S. B.; Kwon, H. J.; Nam, I.-S.; Song, Y. I.; Oh, S. H. Activity Function for Describing Alteration of Three-Way Catalyst Performance over Palladium-Only Three-Way Catalysts by Catalyst Mileage. Ind. Eng. Chem. Res. 2011, 50, 5499-5509.

(9) Ramanathan, K.; Sharma, C. S. Kinetic Parameters Estimation for Three Way Catalyst Modeling. Ind. Eng. Chem. Res. 2011, 50, 9960-9979.

(10) Guan, B.; Zhan, R.; Lin, H.; Huang, Z. Review of the state-ofthe-art of exhaust particulate filter technology in internal combustion engines. J. Environ. Manage. 2015, 154, 225-258.

(11) Joshi, A.; Johnson, T. V. Gasoline Particulate Filters-a Review. Emiss. Contr. Sci.Technol. 2018, 4, 219-239.

(12) Shao, H.; Carpentier, G.; Yin, D.; Wang, Y.; Remias, J.; Roos, J.; Xia, W.; Zheng, Y.; Yuan, X.; Yang, D.; He, X.; Yin, Z. Engine Accelerated Aging Method Developed to Study the Effect of Lubricant Formulations on Catalyzed Gasoline Particulate Filter Durability; SAE Technical Paper, 2018 2018-01-1804.

(13) Xia, W.; Yuan, X.; Yang, D.; Zheng, Y.; Zhao, D.; Wang, C.; He, X.; Shao, H.; Carpentier, G.; Remias, J.; Roos, J.; Yin, D.; Wang, Y.; Liang, K. J. Design of Catalyzed Gasoline Particulate Filter (cGPF) and Investigation of Its Durability Performance Using Accelerated Engine Aging; SAE Technical Paper, 2019 2019-01-0970.

(14) Lambert, C.; Chanko, T.; Dobson, D.; Liu, X.; Pakko, J. Gasoline Particle Filter Development. Emiss. Contr. Sci. Technol. 2017, $3,105-111$.

(15) Johnson, T.; Joshi, A. Review of Vehicle Engine Efficiency and Emissions. SAE Int. J. Engines 2018, 11, 1307-1330.

(16) Opitz, B.; Drochner, A.; Vogel, H.; Votsmeier, M. An experimental and simulation study on the cold start behaviour of particulate filters with wall integrated three way catalyst. Appl Catal B 2014, 144, 203-215.

(17) Mitsouridis, M. A.; Karamitros, D.; Koltsakis, G. Model-Based Analysis of TWC-Coated Filters Performance. Emiss. Contr. Sci. Technol. 2019, 5, 238-252.

(18) Arunachalam, H.; Pozzato, G.; Hoffman, M. A.; Onori, S. In Modeling the thermal dynamics inside a ceria-coated Gasoline Particulate Filter; 2017 IEEE Conference on Control Technology and Applications (CCTA), 2017; 99-105.

(19) Xia, W.; Zheng, Y.; He, X.; Yang, D.; Shao, H.; Remias, J.; Roos, J.; Wang, Y. Catalyzed Gasoline Particulate Filter (GPF) Performance: Effect of Driving Cycle, Fuel, Catalyst Coating; SAE International, 2017 2017-01-2366.

(20) Seong, H.; Choi, S.; Lee, S.; Zaluzec, N. J.; Toops, T. J.; Lance, M. J.; Kim, D.; Nguyen, K. Deactivation of Three-Way Catalysts Coated within Gasoline Particulate Filters by Engine-Oil-Derived Chemicals. Ind. Eng. Chem. Res. 2019, 58, 10724-10736. 
(21) De Abreu Goes, J.; Woo, J. W.; Olsson, L. Effects of Feed Gas Composition on Fresh and Aged TWC-Coated GPFs Loaded with Real Soot. Ind. Eng. Chem. Res. 2020, 59, 10790-10803.

(22) Di Monte, R.; Fornasiero, P.; Kašpar, J.; Graziani, M.; Gatica, J. M.; Bernal, S.; Gómez-Herrero, A. Stabilisation of nanostructured $\mathrm{Ce}_{0.2} \mathrm{Zr}_{0.8} \mathrm{O}_{2}$ solid solution by impregnation on $\mathrm{Al}_{2} \mathrm{O}_{3}$ : a suitable method for the production of thermally stable oxygen storage/release promoters for three-way catalysts. Chem. Commun. 2000, 21, 21672168.

(23) Kaspar, J.; Fornasiero, P.; Balducci, G.; Di Monte, R.; Hickey, N.; Sergo, V. Effect of $\mathrm{ZrO}_{2}$ content on textural and structural properties of $\mathrm{CeO}_{2}-\mathrm{ZrO}_{2}$ solid solutions made by citrate complexation route. Inorg. Chim. Acta 2003, 349, 217-226.

(24) He, X.; He, J.; Meng, M. Perovskite-Based Lean-Burn NOxTrap Catalysts Without Using Platinum Group Metals: $\mathrm{K} / \mathrm{LaCoO}_{3} / \mathrm{Ce}_{1}-$ $\mathrm{xZrxO}_{2}$. Catal. Lett. 2011, 141, 1364.

(25) Wurzenberger, J. C.; Triebl, C.; Kutschi, S. Diffusion Supporting Passive Filter Regeneration- A Modeling Contribution on Coated Filters; SAE Technical Paper, 2018 2018-01-0957.

(26) Łojewska, J.; Kołodziej, A. Engineering aspects of catalytic converters designs for cleaning of exhaust gases. In New and Future Developments in Catalysis : Catalysis for Remediation and Environmental Concerns; edited by Suib, S. L.; Elsevier: Tokio, 2013, 257-279

(27) Etheridge, J. E.; Watling, T. C. Is reactor light-off data sufficiently discriminating between kinetic parameters to be used for developing kinetic models of automotive exhaust aftertreatment catalysts? The effect of hysteresis induced by strong self inhibition. Chem. Eng. J. 2015, 264, 376-388.

(28) Hlaváček, V.; Votruba, J. Experimental Study of Multiple Steady States in Adiabatic Catalytic Systems. In Chemical Reaction Engineering-II; American chemical society, 1975, 133, 545 -558.

(29) Hlaváček, V. R. H.; Prins, W.; Van Swaaij, W. P. M. Platinum catalyzed oxidation of carbon monoxide as a model reaction in mass transfer measurements. Chem. Eng. Sci. 1998, 53, 3355-3366.

(30) NIST Chemistry WebBook; https://webbook.nist.gov/ (03/ 2020),

(31) Gerberich, H. Catalytic oxidation I. The oxidation of ethylene over Pd and Pd-Au alloys. J. Catal. 1970, 16, 204-219.

(32) Lang, W.; Harold, M. P. Rate Inhibition and Enhancement on Ceria-Promoted Pd Monolith Catalysts: Oxidation of Acetylene, Ethylene, and Propylene and Their Mixtures. Ind. Eng. Chem. Res. 2019, 58, 6350-6363.

(33) Getsoian, A. B.; Theis, J. R.; Lambert, C. K. Sensitivity of Three-Way Catalyst Light-Off Temperature to Air-Fuel Ratio. Emiss. Contr. Sci.Technol. 2018, 4, 136-142.

(34) Yao, Y. The oxidation of $\mathrm{CO}$ and hydrocarbons over noble metal catalysts. J. Catal. 1984, 87, 152-162.

(35) Gong, J.; Wang, D.; Li, J.; Currier, N.; Yezerets, A. Dynamic oxygen storage modeling in a three-way catalyst for natural gas engines: A dual-site and shrinking-core diffusion approach. Appl Catal B 2017, 203, 936-945.

(36) Mandapaka, R.; Madras, G. Aluminium and rhodium co-doped ceria for water gas shift reaction and CO oxidation. Mol. Catal. 2018, 451, 4-12.

(37) Gremminger, A. T.; Pereira De Carvalho, H. W.; Popescu, R.; Grunwaldt, J.-D.; Deutschmann, O. Influence of gas composition on activity and durability of bimetallic $\mathrm{Pd}-\mathrm{Pt} / \mathrm{Al}_{2} \mathrm{O}_{3}$ catalysts for total oxidation of methane. Catal. Today 2015, 258, 470-480.

(38) Millet, C.-N.; Benramdhane, S. A 3WCC Global Kinetic Model: A Calibration Method Using Laboratory Scale and Engine Test Bench Experiments; SAE Technical Paper, 2008 2008-01-0453.

(39) Berlowitz, P. J.; Peden, C. H. F.; Goodman, D. W. Kinetics of carbon monoxide oxidation on single-crystal palladium, platinum, and iridium. J. Phys. Chem. 1988, 92, 5213-5221.

(40) Hoebink, J. H. B. J.; Harmsen, J. M. A.; Balenovic, M.; Backx, A. C. P. M.; Schouten, J. C. Automotive Exhaust Gas Conversion: From Elementary Step Kinetics to Prediction of Emission Dynamics. Top. Catal. 2001, 16, 319-327.
(41) Galdikas, A.; Descorme, C.; Duprez, D.; Dong, F.; Shinjoh, H. Study of the Oxygen Diffusion on Three-Way Catalysts: A Kinetic Model. Top. Catal. 2004, 30/31, 405-409.

(42) Shwan, S.; Partridge, W.; Choi, J.-S.; Olsson, L. Kinetic Modeling of NOx Storage and Reduction using Spatially Resolved MS Measurements. Appl Catal B 2014, 147, 1028-1041.

(43) Han, Z.; Wang, J.; Yan, H.; Shen, M.; Wang, J.; Wang, W.; Yang, M. Performance of dynamic oxygen storage capacity, water-gas shift and steam reforming reactions over Pd-only three-way catalysts. Catal. Today 2010, 158, 481-489.

(44) Tysoe, W.; Nyberg, G.; Lambert, R. Structural, kinetic, and reactive properties of the palladium (111)-ethylene system. J. Phys. Chem. 1984, 88, 1960-1963.

(45) Mohsin, S. B.; Trenary, M.; Robota, H. J. Identification of ethylene-derived species on alumina-supported rhodium, iridium, palladium and platinum catalysts by infrared spectroscopy. J. Phys. Chem. 1991, 95, 6657-6661.

(46) Nibbelke, R. H.; Kreijveld, R. J. M.; Hoebink, J. H. B. J.; Marin, G. B. Kinetic Study of the Ethene Oxidation by Oxygen in the Presence of Carbon Dioxide and Steam over $\mathrm{Pt} / \mathrm{Rh} / \mathrm{CeO}_{2} / \gamma-\mathrm{Al}_{2} \mathrm{O}_{3}$. In Studies in Surface Science and Catalysis; Kruse, N.; Frennet, A.; Bastin, J. M., Eds. Elsevier: 1998; Vol. 116, 389-398.

(47) Yeo, Y. Y.; Stuck, A.; Wartnaby, C. E.; Kose, R.; King, D. A. Microcalorimetric study of ethylene adsorption at $300 \mathrm{~K}$ on $\mathrm{Pt}\{100\}$ hex and Pt $\{100\}-(1 \times 1)$. J. Mol. Catal. A: Chem. 1998, 131, 31-38.

(48) Harmsen, J. M. A.; Hoebink, J. H. B. J.; Schouten, J. C., Transient kinetics of ethylene and carbon monoxide oxidation for automotive exhaust gas catalysis: experiments and modelling. In Studies in Surface Science and Catalysis, Froment, G. F.; Waugh, K. C., Eds. Elsevier, 1999, 122, 101-108.

(49) Harmsen, J. M. A.; Hoebink, J. H. B. J.; Schouten, J. C. Transient Kinetic Modeling of the Ethylene and Carbon Monoxide Oxidation over a Commercial Automotive Exhaust Gas Catalyst. Ind. Eng. Chem. Res. 2000, 39, 599-609.

(50) Hill, J. M.; Shen, J.; Watwe, R. M.; Dumesic, J. A. Microcalorimetric, Infrared Spectroscopic, and DFT Studies of Ethylene Adsorption on Pd and Pd/Sn Catalysts. Langmuir 2000, $16,2213-2219$.

(51) Vattuone, L.; Yeo, Y. Y.; Kose, R.; King, D. A. Energetics and kinetics of the interaction of acetylene and ethylene with $\operatorname{Pd}\{100\}$ and $\mathrm{Ni}\{100\}$. Surf. Sci. 2000, 447, 1-14.

(52) Ordóñez, S.; Bello, L.; Sastre, H.; Rosal, R.; Díeze, F. V. Kinetics of the deep oxidation of benzene, toluene, $n$-hexane and their binary mixtures over a platinum on $\gamma$-alumina catalyst. Appl Catal B 2002, 38, 139-149.

(53) Morales-Torres, S.; Pérez-Cadenas, A. F.; Kapteijn, F.; Carrasco-Marín, F.; Maldonado-Hódar, F. J.; Moulijn, J. A. Palladium and platinum catalysts supported on carbon nanofiber coated monoliths for low-temperature combustion of BTX. Appl Catal B 2009, 89, 411-419.

(54) Lopez-Gonzalez, D.; Tsampas, M. N.; Boréave, A.; RetailleauMevel, L.; Klotz, M.; Tardivat, C.; Cartoixa, B.; Pajot, K.; Vernoux, P. Mixed Ionic-Electronic Conducting Catalysts for Catalysed Gasoline Particulate Filters. Top. Catal. 2015, 58, 1242-1255.

(55) Li, B.; Song, C.; Lv, G.; Chen, K.; Cao, X. Impact of Soot on NOx Adsorption over Cu-Modified Hydrotalcite-Derived Lean NOx Trap Catalyst. Langmuir 2017, 33, 2939-2948. 